\title{
Economic analysis for centralized battery energy storage system with reused battery from EV in Australia
}

\author{
Yunfan Meng* \\ School of Photovoltaic and Renewable Energy Engineering, SPREE \\ The University of New South Wales, Sydney, Australia
}

\begin{abstract}
With battery energy storage technology development, the centralized battery energy storage system (CBESS) has a broad prospect in developing electricity. In the meantime, the retired lithium-ion batteries from electric vehicles (EV) offer a new option for battery energy storage systems (BESS). This paper studies the centralized reused battery energy storage system (CRBESS) in South Australia by replacing the new lithium-ion batteries with lithium-ion second-life batteries (SLB) and evaluating the economic benefits with economic indicators as net present value (NPV), discounted payback period (DPBP), Internal rate of return (IRR) to depict a comprehensive understanding of the development potential of the CRBESS with the lithium-ion SLB as the energy storage system. This paper proposes a calculation method of frequency control ancillary services (FCAS) revenue referring to market share rate (MSR) when building the economic model. Moreover, the residual value of lithium-ion batteries is considered. This paper uses the economic model to calculate the profitability and development potential of CRBESS. From an economic perspective, the superiority and feasibility of CRBESS compared with CBESS were analyzed.
\end{abstract}

\section{Introduction \& Context}

The global energy storage market is developing rapidly. According to a forecast, by 2022 , the energy storage market's annual sales can reach over US\$26 billion, with a compound annual growth rate of $46.5 \%[1]$. Another analysis predicts that its growth may be more gradual but still firm. This analysis signifies that by 2025 , the global energy storage market will grow at a compound annual growth rate of $16 \%$, and annual sales will reach US\$7 billion[2]. Globally, energy storage capacity increased by $2.9 \mathrm{GW}$ in 2019 , down nearly $30 \%$ from 2018, marking the global energy storage market's first contraction in a decade[3].

Battery energy storage is a promising energy storage technology in Australia. According to the Smart Energy Council's forecast report on the Australian energy storage market, Australia will add $1 \mathrm{GW}$ to $3 \mathrm{GW}$ of battery energy storage systems by 2020 [4].

The rapid development of battery energy storage is inseparable from decreased cost and improved technology performance, especially in lithium-ion batteries. Meanwhile, benefiting

* Corresponding author: yunfan.meng@unswalumni.com 
from the rapid growth of electric vehicle technology, lithium-ion batteries' quantity and manufacturing process have been significantly increased. Transferring lithium-ion batteries caused by overproduction in manufacturing or retired lithium-ion batteries from electric vehicles to grid-scale applications has become a new choice. The retired lithium-ion SLB of electric vehicles has a lower cost than new batteries [5, 6]. Generally, when a new battery's capacity degrades to $70-80 \%$, it cannot meet the requirements of electric vehicles[7]. These batteries can be returned to the market as SLB after they have been repaired and passed a performance test series. The lithium-ion SLB can fully meet the requirements of the battery energy storage system[8].

In 2019, electric vehicles' global sales exceeded 2.1 million, bringing the stock of electric vehicles to 7.2 million[9]. In 2020, the first batch of electric vehicle batteries had reached their retirement age, and in the next ten years, the number of retired batteries will increase sharply. By 2030, the SLB capacity from electric vehicles will reach $275 \mathrm{GWh}[10]$. It provides a massive opportunity for battery energy storage. The application of SLB from an electric vehicle to centralized battery energy storage systems conforms to the rapid development trend of the energy storage market in Australia and solves the problem of the use of retired batteries and reduces energy waste. It could also achieve the goal of sustainable development.

Therefore, this paper analyzes the economic benefits of using the lithium-ion SLB from the electric vehicle as a centralized energy storage system in the Australian grid and compares it with the centralized energy storage system with new batteries to understand the potential development of CRBESS in Australia comprehensively. This paper's contributions include: First, a new auxiliary market revenue calculation model is proposed, which combines MCR to make the economic models of CBESS and CRBESS more accurate. The second uses economic indicators NPV, DPBP, and IRR to compare the economic benefits of CBRESS and CBESS and consider the recycling revenue of lithium-ion batteries. Because the residual value of lithium-ion is considerable, it is included in the economic evaluation process. Third, through energy storage configuration optimization, forecast the future development of CRBESS. Fourth, analyze the economic sensitivity of NPV and IRR, and find the economically sensitive factors of CRBESS and CBESS from investment and profit, to improve the economic benefits.

\section{Methodology}

\subsection{Data \& Assumptions}

Table 1. Technical data assumptions for CBESS and CRBESS.

\begin{tabular}{|c|c|c|c|}
\hline Variable & CBESS & CBRESS & Unit \\
\hline Power & 100 & 100 & MW \\
\hline Capacity & 100 & 100 & MWh \\
\hline Design life & 20 & 20 & Year \\
\hline DoD & $80[12-15]$ & $80[6,20,21]$ & $\%$ \\
\hline Lifecycle & $3000[12-15]$ & $3000[6,20,21]$ & \\
\hline Round trip efficiency & $95[16,17]$ & $95[22-25]$ & $\%$ \\
\hline Annual Degradation Rate & $2.8[18]$ & $3.3[26]$ & $\%$ \\
\hline Capacity reduction rate & 0 & 80 & $\%$ \\
\hline
\end{tabular}

The following study details various technical parameters for CBESS. Assume that a CBESS $(100 \mathrm{MW} / 100 \mathrm{MWh})$ is built in South Australia with a design life of 20 years. BESS uses lithium-ion batteries because most of the reused batteries from EV are lithium-ion batteries[11]. Compared with CBESS, CRBESS only changed the type of battery, replacing 
the new lithium-ion-ion battery with a lithium-ion SLB retired from EV. After the retired battery of an electric vehicle is returned to the factory for repair, the capacity will become $80 \%$ of the new battery[19]. Therefore, in CRBESS uses lithium-ion SLB modeling, its capacity reduction rate is $80 \%$. All the technical assumptions for CBESS and CRBESS are listed in Table 1 with references.

\subsection{Economic Model}

The project's economic benefit significantly affects investors' investment willingness [27], which is also an important indicator to evaluate the development potential of CBESS and CRBESS.

\subsubsection{Cost Model}

The project's cost model consists of four parts: initial cost, operation and maintenance cost, energy loss cost, and replacement cost. The following chapters will introduce the calculation method of each cost in detail.

The project's initial cost includes capital cost, power conversion system cost, the balance of plant cost, construction, and commissioning cost. Where $C_{i n i}$ is the initial cost of the project (\$), $C_{\text {cap }}$ is the cost of BESS in purchasing a direct current (DC) energy storage unit, the unit is $(\$ / \mathrm{kWh}) . C_{p c s}$ is the cost of the power conversion system. Because the connection between BESS and the grid requires rectification and inverter processes, and the PCS includes rectifiers, inverters, and controllers needed for the procedure, PCS cost consists of the cost of packaging in addition to the cost of the above equipment, and the unit is $(\$ / \mathrm{kW})[28] . C_{\text {bop }}$ is the balance of plant cost, which includes the cost of transformers and other auxiliary equipment, as well as the cost of wiring, the unit is $(\$ / \mathrm{kW})[29] . \quad C_{C \& C}$ is the cost of construction and commissioning, includes site design costs, costs related to equipment purchase/transportation, labor costs, the unit is $(\$ / \mathrm{kWh})[29]$.

The equation is shown as follow:

$$
C_{i n i}=C_{c a p} \times E+C_{p c s} \times P+C_{b o p} \times P+C_{C \& C} \times E
$$

The operation and maintenance costs include fixed operations and maintenance costs and variable operations and maintenance costs. Where $C_{o \& m}$ is the cost of operation and maintenance $(\$), C_{f_{-} o \& m}$ is the fixed operations and maintenance cost includes the operations and maintenance cost of BESS during the life cycle, which is normalized with the rated power, the unit is $(\$ / \mathrm{kW}) . C_{v_{-} o \& m}$ is the cost of variable operation and maintenance; it includes all costs to operate the BESS, which normalized with the annual energy discharge, the unit is $(\$ / \mathrm{kWh})$. Fixed O\&M cost includes labor cost, daily operation and maintenance, planned maintenance, and other general costs[28]. Variable O\&M cost includes consumables for energy storage and maintenance of large equipment. Few resources provide specific variable O\&M cost values[30, 31].

The equation is shown as follow:

$$
C_{o \& m}=C_{f_{-} o \& m} \times P+C_{v_{-} o \& m} \times E
$$

The energy loss cost is the power loss caused by RTE, which could have been sold back to the grid. The equation is shown as follow:

$$
C_{\text {loss }}=E \times D o D \times(1-R T E) \times M_{\text {peak }}
$$


Where $C_{\text {loss }}$ is the cost of energy loss $(\$), D o D$ is the value of depth of discharge (\%), $R T E$ is the value of round-trip efficiency (\%), $M_{\text {peak }}$ is the time-of-use (ToU) peak price $(\$ / \mathrm{kWh})$.

The replacement cost is battery replacement and the PCS's major maintenance to keep the system operational. The equation is shown as follow:

$$
C_{r e}=C_{c a p} \times E+C_{p c s} \times P+C_{C \& C} \times E
$$

Considering the time value of money, it is necessary to calculate future costs in the first year. The equation is shown as follows:

$$
\begin{gathered}
r=\frac{d-i}{1+i} \\
C=\sum_{1}^{n}\left(\frac{C_{o \& m}}{1+r}\right)^{t_{s}}+\sum_{1}^{n}\left(\frac{C_{\text {loss }}}{1+r}\right)^{t_{s}}+\sum_{1}^{t}\left(\frac{C_{r e}}{1+r}\right)^{t_{r}}+C_{\text {ini }}
\end{gathered}
$$

Where $C$ is the total cost of BESS in the design life (\$), $d$ is the nominal discounted rate (\%), and $i$ is the inflation rate (\%), respectively. $r$ is the real discounted rate. $n$ is the total lifetime of the project (year), $t_{s}$ is the used time (year), $t$ is the replacement times during the design life (year), $t_{r}$ is the year of replacement (year).

\subsubsection{Revenue model}

The revenue model of the project consists of three parts: energy arbitrage revenue, ancillary service revenue, and battery recycle revenue.

The energy arbitrage uses the time-of-use electricity prices to earn the difference between charging and discharging, which is discharging in peak price period and charging in off-peak price period[32].

The equation is shown as follows:

$$
\begin{gathered}
R_{e a}=\left(E_{\text {dis }} \times M_{\text {peak }}-E_{\text {cha }} \times M_{\text {off-peak }}\right) \times 365 \\
R_{e a}=\left(\begin{array}{c}
E \times \operatorname{Dod} \times R T E \times M_{\text {peak }} \\
-E \times \operatorname{Dod} \times M_{\text {off-peak }}
\end{array}\right) \times 365
\end{gathered}
$$

Where $R_{e a}$ is the revenue of energy arbitrage (\$), $M_{\text {peak }}$ and $M_{\text {off-peak }}$ are the ToU peak price and off-peak price $(\$ / \mathrm{kWh})$, respectively. According to the 2020-2025 tariff structure statement published by SA Power Networks, Small Business $(<160 \mathrm{MWh})$ tariff structure and charging parameters are shown in Table 2.

Table 2. Tariff structure statement for small business $(<160 \mathrm{MWh})[33]$.

\begin{tabular}{|c|c|c|c|}
\hline & Time & Price & Unit \\
\hline Peak & $5: 00 \mathrm{pm}-9: 00 \mathrm{pm}$ & 0.2253 & $\$ / \mathrm{kWh}$ \\
\hline Off-peak & All other time & 0.1568 & $\$ / \mathrm{kWh}$ \\
\hline
\end{tabular}

Australian Energy Market Operator (AEMO) uses frequency Control Auxiliary Service (FCAS) to safely and reliably maintain the electric power system's frequency stability. The FCAS benefiting process for BESS can be roughly described as: AEMO predicts the FCAS demand in the next 5 minutes based on the real-time collected data information from supervisory control and data acquisition (SCADA), and then allocates market supply according to the BESS registered capacity with AEMO and the bidding price for ancillary service. BESS is paid according to the number of ancillary services provided and the price of ancillary services. The national electricity market dispatch engine (NEMDE) determines the 
clearing price of eight FCAS markets for every dispatch interval, and the FCAS provider will be paid based on this price[34]. The calculation formula of remuneration is as follow:

$$
M_{\text {payment }}=E_{M W} \times M_{\text {clearing }} \div 12
$$

Where the $M_{\text {payment }}$ is the payment for FCAS providers (\$), $E_{M W}$ is the amount of capacity enabled by NEMDE (MW), $M_{\text {clearing }}$ is the clearing price in the dispatch interval (\$/MW).

Usually, the clearing price unit is $\$ / \mathrm{MW} /$ hour, but the dispatch interval is 5 minutes, and the FCAS provider will also get paid every 5 minutes[34]. The FCAS provider's payment will be provided by the participant who caused the frequency change[34]. The equation is shown as follow:

$$
R_{\text {FCAS }}=R_{\text {Freg }}+R_{\text {Fcon }}
$$

Where $R_{F C A S}$ is the revenue of frequency control ancillary services $(\$), R_{\text {Freg }}$ is the revenue of Regulation FCAS (\$), $R_{F c o n}$ is the revenue of Contingency FCAS (\$). Assume that the BESS registers all eight FCAS markets. According to the Aurecon report in 2019, a large-scale battery energy storage system generally registers its total charge/discharge capacity in Regulation raise/lower FCAS markets, registers in contingency FCAS markets by following the requirements from AEMO[44]. The calculation of the Contingency FCAS capacity formula is shown below.

$$
E_{r-F c o n}=100 \times \frac{1}{r_{D}} \times \frac{\left(\min \left(F_{d e v}, F_{d i f}\right)-F_{d e a}\right)}{50} \times P
$$

Where $E_{r-F c o n}$ is the registered capacity in Contingency FCAS markets of BESS (MW), $r_{D}$ is the droop rate (\%) whose minimum value is $1.7 \%$ for any BESS regardless of its capacity, $F_{\text {dev }}$ is the maximum battery charge or discharge frequency deviation, which is 1 , $F_{\text {dif }}$ is the absolute value of frequency difference between $50 \mathrm{~Hz}$ and reference frequency, which is $0.5, F_{\text {dea }}$ is the frequency dead band, which is 0.15 . The result needs to be rounded down[35].

AEMO purchases FCAS (MW) volume required for each dispatch interval from different FCAS providers, based on their registered capacity and bidding price. Therefore, the profitability of FCAS providers is determined by their market participation and registration capacity.

$$
R_{F C A S}=\left(\begin{array}{c}
E_{m-\text { regr }} \times M_{\text {regr }} \times \alpha \\
+E_{m-\text { regl }} \times M_{\text {regl }} \times \beta \\
+E_{r-\text { conr } 6 s} \times M_{\text {conr } 6 s} \\
+E_{r-\text { conr } 60 s} \times M_{\text {conr } 60 s} \\
+E_{r-\text { conr } 5 \text { min }} \times M_{\text {conr } 5 \text { min }} \\
+E_{r-\text { conl6s }} \times M_{\text {conl6s }} \\
+E_{r-\text { conl60s }} \times M_{\text {conl60s }} \\
+E_{r-\text { conl } 5 \text { min }} \times M_{\text {conl5min }}
\end{array}\right) \div 12 \times 365 \times 24 \times 12
$$

Where $E_{m-r e g r}, E_{m-r e g l}$ refer to the regulation raise FCAS market procurement (MW) and the Regulation lower FCAS market procurement (MW).

$E_{r-\text { conr6s }}, E_{r-\text { conr60s }}, E_{r-\text { conr } 5 \text { min }}, E_{r-\text { conl6s }}, E_{r-\text { conl60s }}, E_{r-\text { conl5min }}$ refer to the registered capacity of BESS in the contingency raise 6s FCAS market, contingency raise $60 \mathrm{~s}$ FCAS market, contingency raise 5min FCAS market, Contingency lower 6s FCAS market, Contingency lower 60s FCAS market, contingency 5min FCAS market (MW), respectively. 
$\alpha, \quad \beta$ refer to the market share rate in regulation raise/lower FCAS markets (\%).

$M_{\text {regr }}, M_{\text {regl }}, M_{\text {conr6s }}, M_{\text {conr60s }}, M_{\text {conr } 5 \min }, M_{\text {conl6s }}, M_{\text {conl60s }}, M_{\text {conl5min }}$ refer to the average clearing price in eight FCAS markets ( $\$ / \mathrm{MW} /$ hour).

At the end of the use phase, the anode metal can be disassembled and recovered to recover the residual value. The recycle revenue equation is shown as follows:

$$
\begin{gathered}
R_{\text {recycle }}=R_{\text {lithium }}+R_{\text {iron }}+R_{\text {al }}+R_{\text {copper }} \\
R_{\text {recycle }}=\frac{E \times 1000}{D_{\text {battery }} \times 1000} \times\left[\begin{array}{c}
\left(W_{\text {lithium }} \times M_{\text {lithium }}\right) \\
+\left(W_{\text {iron }} \times M_{\text {iron }}\right) \\
+\left(W_{\text {al }} \times M_{\text {al }}\right) \\
+\left(W_{\text {copper }} \times M_{\text {copper }}\right)
\end{array}\right]
\end{gathered}
$$

Where $R_{\text {recycle }}$ is the battery recycle revenue $(\$), D_{\text {battery }}$ is the battery energy density $(\mathrm{kWh} / \mathrm{kg}), W_{\text {lithium }}, W_{\text {iron }}, W_{\text {al }}, W_{\text {copper }}$ are the weight of lithium, iron, aluminum, and copper (kg/ton), respectively. $M_{\text {lithium }}, M_{\text {iron }}, M_{a l}, M_{\text {copper }}$ are the price of lithium, iron, aluminum, and copper (\$/ton), respectively.

The total revenue in the design life equation is shown in equation (16) below where $R$ is the total revenue in the design life (\$).

$$
R=\sum_{1}^{n}\left[\frac{R_{e a}}{1+r}\right]^{t_{s}}+\sum_{1}^{n}\left[\frac{R_{F C A S}}{1+r}\right]^{t_{s}}+\sum_{1}^{t}\left\{\frac{R_{\text {recycle }}}{1+r}\right\}^{t_{r}}
$$

\subsection{Economic index}

Economic indicators can analyze economic performance and predict future performance. When investors make project investment decisions to measure the project's economic benefits, there are many economic indicators used to evaluate the project's feasibility.

The Net present value (NPV) is the difference between the present value of cash inflow and cash outflow over a period, considering the time value of money and the risk-return of investment. If the NPV is positive, it means that the project's expected benefit is higher than the anticipated cost; if the NPV is negative, it means that the investment will result in a net loss[49]. The equation is shown as follows:

$$
N P V_{L S}=-C_{\text {ini }}+\sum_{1}^{n}\left(\frac{C F_{\text {in }}-C F_{\text {out }}}{1+r}\right)^{t_{S}}
$$

The discounted payback period (DPBP) is calculated by discounting the future cash flow to calculate the number of years required to reach the balance of payments from the initial investment. The shorter the discounted payback period, the shorter the time for the project to recover costs. The equation is shown below.

$$
D P B P=t_{s 0}+\frac{N P V_{t s 0}}{C F_{t s 1}}
$$

Where $D P B P$ is the discounted payback period (year), $t_{s 0}$ is the last year with negative $\mathrm{NPV}, N P V_{t s 0}$ is the discounted cumulative cash flow at the end of $t_{s 0}(\$), C F_{t s 1}$ is the discounted cash flow in the next year of $t_{s 0}(\$)$.

The internal rate of return (IRR) is used to estimate the potential investment capacity. It shows the degree of currency depreciation that the project investment income can withstand. A discount rate makes the net present value of all cash flows equal to zero in the discounted cash flow analysis. In general, when the internal rate of return is greater than the actual 
discount rate, the project is feasible. The equation is shown below, where irr is the internal rate of return $(\%)$.

$$
N P V=-C_{\text {ini }}+\sum_{1}^{n}\left(\frac{C F_{\text {in }}-C F_{\text {out }}}{1+\text { irr }}\right)^{t_{s}}=0
$$

\subsection{Economic parameters}

Table 3 below lists all assumed parameters for economic modeling and analysis. Variable O\&M cost is not considered in the following analysis. The life cycle and safety of LiFePO4 are higher, and it is more prevalent in the secondary use market[41]. Therefore, LiFePO4 batteries are the research object in the following analysis.

Table 3. Economic parameters definition [28, 37, 38, 39, 40, 41-44].

\begin{tabular}{|c|c|c|c|c|c|}
\hline \multicolumn{2}{|c|}{ Economic parameter } & \multicolumn{3}{|c|}{ Value } & Unit \\
\hline \multicolumn{2}{|c|}{ Nominal discounted rate } & \multicolumn{3}{|c|}{7} & $\%$ \\
\hline \multicolumn{2}{|c|}{ Inflation rate } & \multicolumn{3}{|c|}{1.97} & $\%$ \\
\hline \multicolumn{2}{|c|}{ Real discounted rate } & \multicolumn{3}{|c|}{4.7} & $\%$ \\
\hline \multicolumn{2}{|c|}{ Market share rate } & \multicolumn{3}{|c|}{10} & $\%$ \\
\hline \multicolumn{2}{|c|}{ Reg Raise market capacity } & \multicolumn{3}{|c|}{130} & MW \\
\hline \multicolumn{2}{|c|}{ Reg Lower market capacity } & \multicolumn{3}{|c|}{120} & MW \\
\hline \multicolumn{2}{|c|}{ Peak price } & \multicolumn{3}{|c|}{225.3} & $\$ / \mathrm{MWh}$ \\
\hline \multicolumn{2}{|c|}{ Off-peak price } & \multicolumn{3}{|c|}{156.8} & $\$ / \mathrm{MWh}$ \\
\hline \multicolumn{2}{|c|}{ Reg Raise Price } & \multicolumn{3}{|c|}{27.97} & \$/MW \\
\hline \multicolumn{2}{|c|}{ Reg Lower Price } & \multicolumn{3}{|c|}{15.06} & $\$ / M W$ \\
\hline \multicolumn{2}{|c|}{ Raise 6s Price } & \multicolumn{3}{|c|}{11.35} & \$/MW \\
\hline \multicolumn{2}{|c|}{ Raise 60s Price } & \multicolumn{3}{|c|}{7.57} & \$/MW \\
\hline \multicolumn{2}{|c|}{ Raise 5min Price } & \multicolumn{3}{|c|}{15.49} & $\$ / M W$ \\
\hline \multicolumn{2}{|c|}{ Lower 6s Price } & \multicolumn{3}{|c|}{0.14} & $\$ / M W$ \\
\hline \multicolumn{2}{|c|}{ Lower 60s Price } & & 0.57 & & $\$ / \mathrm{MW}$ \\
\hline Lower 51 & & & 0.37 & & \$/MW \\
\hline Economic p & ter & CBES & & BESS & Unit \\
\hline Capital & & 250 & & 0 & $\$ / \mathrm{kWh}$ \\
\hline Power Conver & ystem & 270 & & 70 & $\$ / \mathrm{kW}$ \\
\hline Balance 0 & & 99 & & 9 & $\$ / \mathrm{kW}$ \\
\hline Construction and & issioning & 100 & & 00 & $\$ / \mathrm{kWh}$ \\
\hline O\&M F & & 60 & & 0 & \$/kW-year \\
\hline O\&M Va & & 0 & & 0 & \$/kWh-year \\
\hline Energy D & & 0.25 & & 14 & $\mathrm{kWh} / \mathrm{kg}$ \\
\hline Type of material & Weight & Unit & Price & Unit & Efficiency \\
\hline Lithium & 12 & $\mathrm{~kg} /$ ton & 12000 & $\$ /$ ton & $80 \%$ \\
\hline Iron/Steel & 432 & $\mathrm{~kg} /$ ton & 120 & $\$ /$ ton & $52 \%$ \\
\hline Aluminum & 65 & $\mathrm{~kg} / \mathrm{ton}$ & 1900 & $\$ /$ ton & $42 \%$ \\
\hline Copper & 82 & $\mathrm{~kg} / \mathrm{ton}$ & 7000 & $\$ /$ ton & $90 \%$ \\
\hline
\end{tabular}




\section{Results \& Discussion}

The following section analyzes the economic performance of CBESS and CRBESS in detail under the economic model above.

\subsection{Cost composition}

According to Figure 1 and Figure 2 below, among the total cost in the design life of CBESS and CRBESS, O\&M cost is the highest cost, accounting for $30 \%-40 \%$ of the total cost. The initial cost and replacement cost are close in proportion, accounting for $30 \%$ of the total cost. Energy loss cost is the smallest cost item, accounting for only $0.01 \%$ of the total cost. After using lithium-ion SLB, the cost of BESS has dropped by $19.63 \%$ during the design life. The main reason is that the price of lithium-ion SLB is much lower than that of new batteries. Although the cost has fallen, CRBESS still has a high O\&M cost, and its cost proportion has increased significantly.

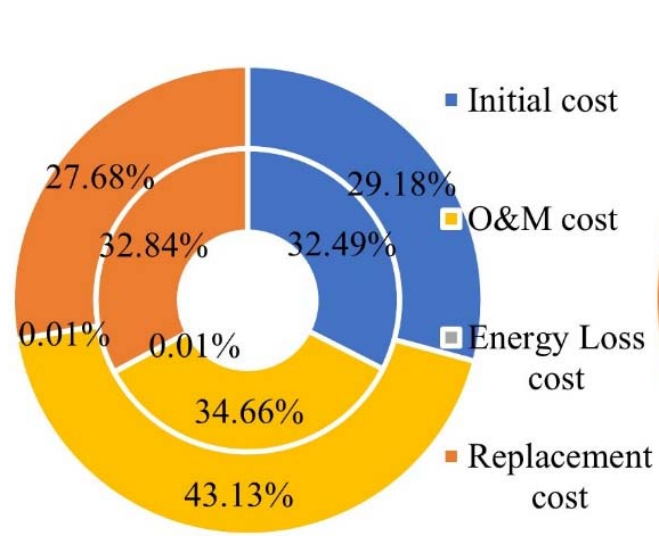

Fig. 1. Percentage of cost for CBESS (inside) vs CRBESS (outside).

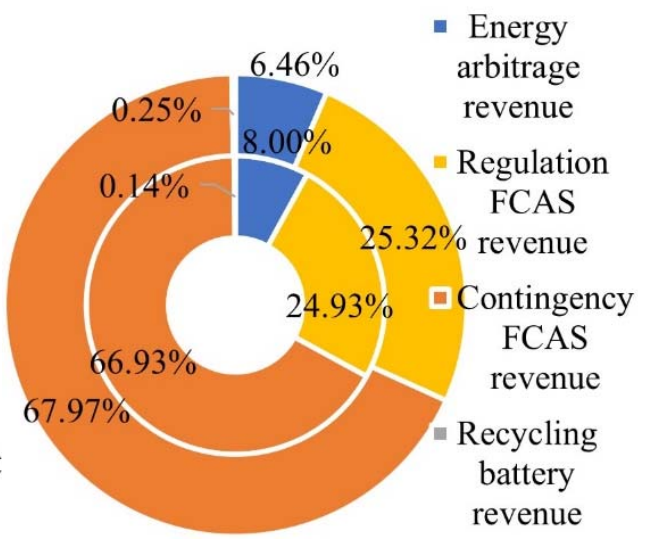

Fig. 2. Percentage of Revenue for CBESS (inside) vs CRBESS (outside).

CBESS and CRBESS mainly benefit from FCAS markets, accounting for $90 \%$ of the total revenue. The revenue of Contingency FCAS is approximately three times that of Regulation FCAS. Figure 3 and Figure 4, changing the new batteries to SLB slightly reduced the energy arbitrage revenue because of the reduction in battery capacity, but almost not influence BESS's revenue in the design life. 


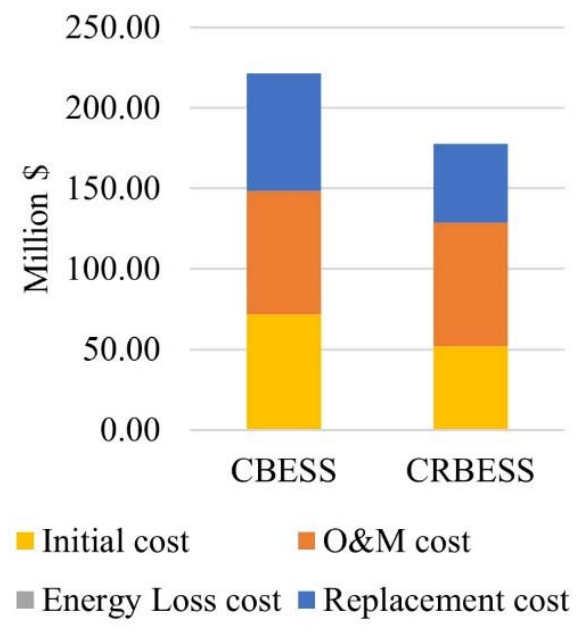

Fig. 3. Cost structure of CBESS vs CRBESS.

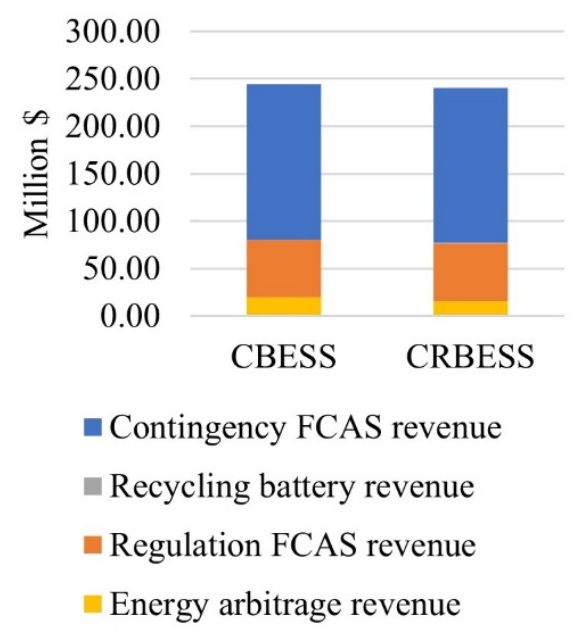

Fig. 4. Revenue structure of CBESS vs CRBESS.

\subsection{Economic indicator results}

Table 4 below shows the economic indicators calculated for CBESS and CBRESS. According to the results, the NPV in the design life and NPV in the battery lifespan of CBESS and CRBESS are positive, which means that both projects are feasible. However, the NPV in the design life of CRBESS is about three times that of CBESS, which indicates that the expected benefits of CRBESS are much higher than CBESS. The discounted payback period of CBRESS is about $30 \%$ shorter than that of CBESS, which means CBRESS can reach the balance of payments faster. The internal rate of return of CBRESS is about two times that of CBESS, which means that CRBESS can withstand a higher currency depreciation, and it has a higher annualized rate for investors. Figure 5 shows the cumulative cash flow and IRR rate of CBESS and CRBESS in the battery lifespan.

Table 4. Economic results of CBESS and CRBESS.

\begin{tabular}{|c|c|c|c|c|}
\hline & $\begin{array}{c}\text { NPV-dl } \\
\text { (million \$) }\end{array}$ & $\begin{array}{c}\text { NPV-ls } \\
\text { (million \$) }\end{array}$ & $\begin{array}{c}\text { DPBP } \\
\text { (year) }\end{array}$ & $\begin{array}{c}\text { IRR } \\
\text { (\%) }\end{array}$ \\
\hline CBESS & 23.23 & 4.78 & 6.34 & 6.78 \\
\hline CRBESS & 62.93 & 22.87 & 4.41 & 16.14 \\
\hline
\end{tabular}




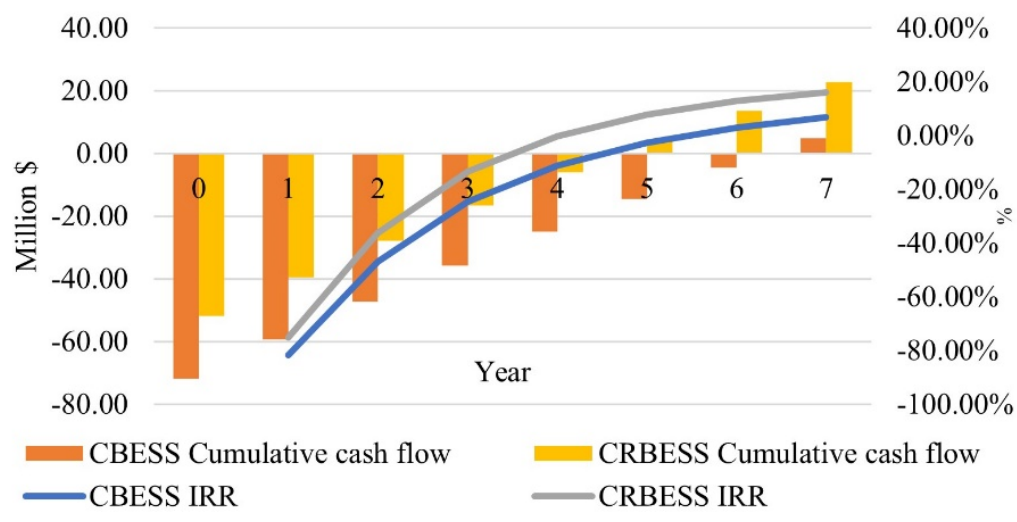

Fig. 5. Cumulative cash flow and IRR of CBESS in battery lifespan.

\subsubsection{BESS configuration optimization}

This section analyzes the configuration optimization of CBESS and CRBESS based on NPV in battery lifespan, and the results are shown in Figure 6 and Figure 7. When NPV-ls is calculated, the MSR value needs to be estimated. Regulation FCAS Markets grows at a slower and smaller rate than BESS. With the increasing scale of BESS, MSR cannot maintain stable growth. Due to the limitation of market size, the MSR growth rate will decline. However, the MSR growth rate should not change within 50MW because AEMO's procurement in the Regulation FCAS Market is expected to increase by 50MW. According to the analysis results, THE NPV of CBESS will peak at about 200MW/200MWh and then decline continuously. The NPV of CRBESS will decrease with the increase of scale, and investors cannot make profits at about $150 \mathrm{MW} / 150 \mathrm{MWh}$. It is because the increase in income cannot balance the input of costs. CBESS still has an ample increment space in the Australian electricity market, while CRBESS has a small increment space.

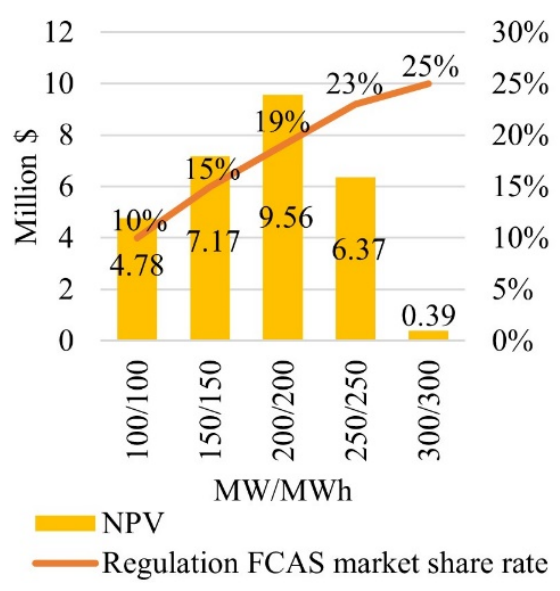

Fig. 6. NPV in battery lifespan with various CBESS scale.

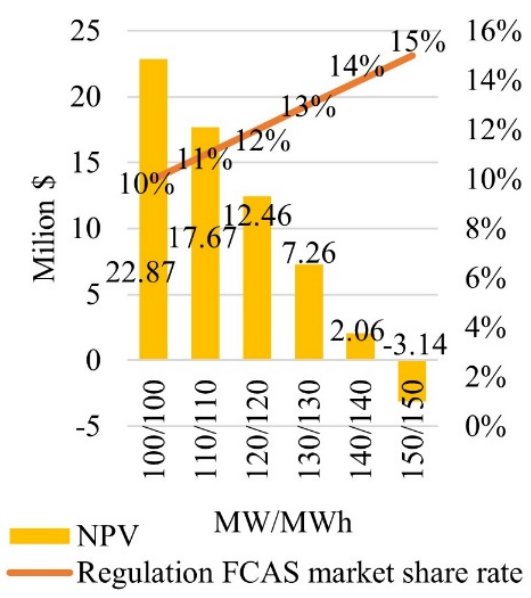

Fig. 7. NPV in battery lifespan with various CRBESS scale.

\subsubsection{Sensitivity analysis}

Sensitivity analysis is aimed to analyze uncertainty in the economic performance of a project. 
Analyze multiple sensitive factors that impact economic indicators, measure their impact on economic indicators, and then judge the project's ability to withstand risks. NPV and IRR are researched in the following study, representing the project's profitability and investment ability.

The sensitivity analysis for NPV in the battery lifespan of CBESS and CRBESS is shown in Figures 8 and 9. According to the results, O\&M cost has the most significant influence on BESS'S NPV in battery life. In contrast, raising the FCAS market has a more significant influence on BESS's NPV than that of the Lower FCAS market. Price difference refers to the difference between peak and off-peak prices, affecting BESS's revenue on energy arbitrage. Compared with CBESS, CRBESS profitability was reduced by the price difference and significantly reduced by capital cost.

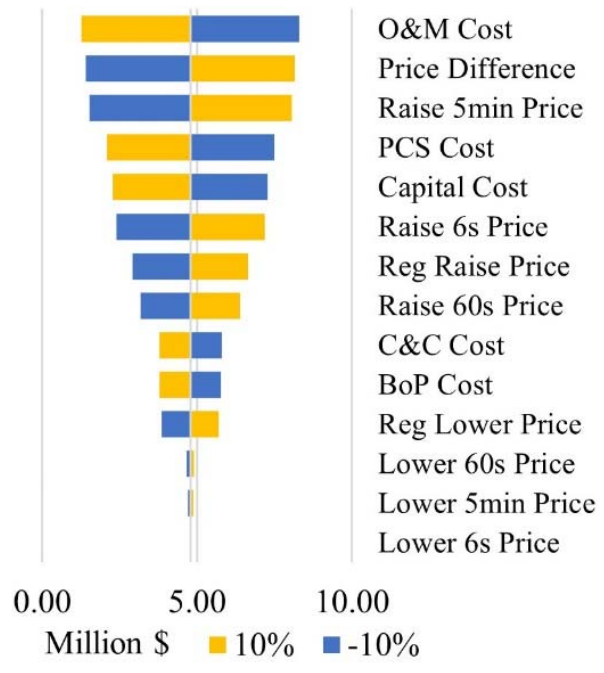

Fig. 8. Sensitivity of CBESS NPV in the battery lifespan.

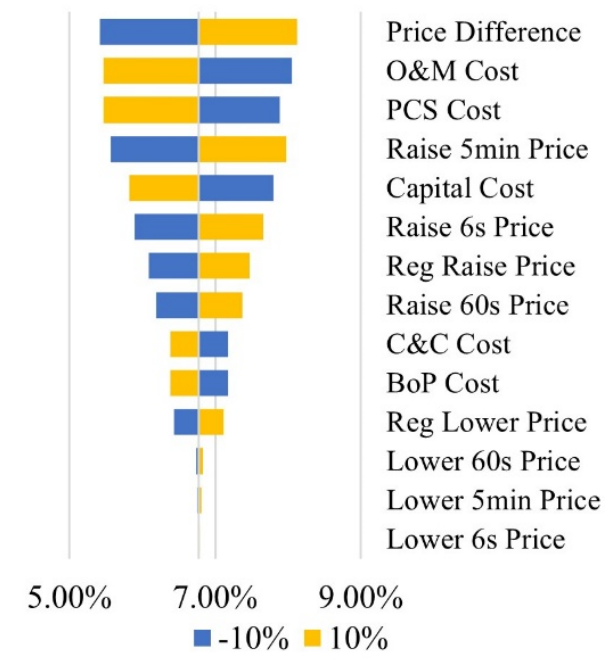

Fig. 10. Sensitivity of CBESS IRR in the battery lifespan.

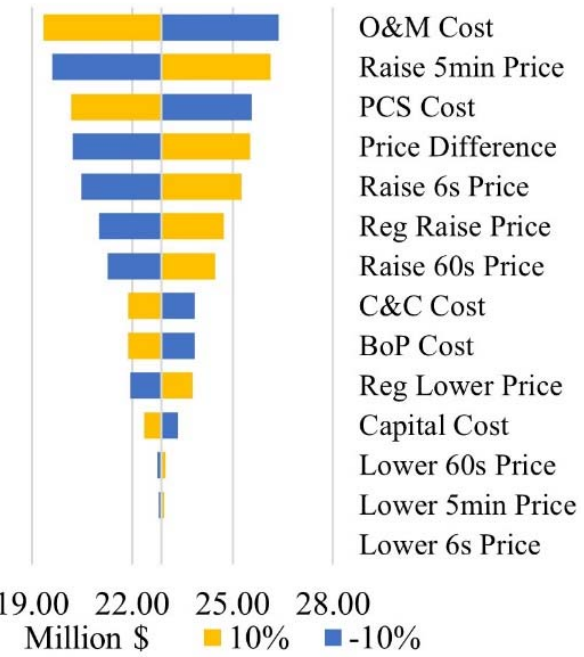

Fig. 9. Sensitivity of CRBESS NPV in the battery lifespan.

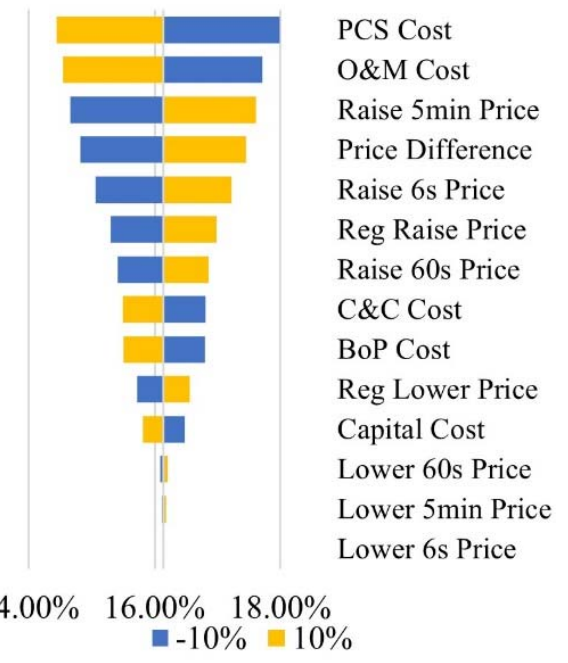

Fig. 11. Sensitivity of CRBESS IRR in the battery lifespan.

The sensitivity analysis for IRR in the battery lifespan of CBESS and CRBESS is shown 
in Figures 10 and 11. According to the results, For BESS, the top three factors affecting IRR are price difference, O\&M cost, and PCS cost. For CRBESS, the impact of the price difference on IRR is slightly smaller than that of CBESS, but the impact of capital cost on IRR is much more significant than CBESS.

\section{Conclusion}

The use of lithium-ion SLB from EV to build a centralized battery energy storage system in Australia is found to have economic benefits compared with new batteries. Under the same conditions, The NPV of CRBESS is about three times that of CBESS, the IRR is about two times that of CBESS, and the payback period is about $2 / 3$ of that of CBESS.

From the analysis of cost composition and revenue composition, it can be found that after using lithium-ion SLB, the cost of BESS has dropped by $30 \%$, and the revenue is almost unchanged. Because the lithium-ion SLB is lower than that of new batteries, the technical performance of the battery has not changed significantly. The main difference between the lithium-ion SLB and the new battery is the battery capacity, which mainly affects BESS's revenue in energy arbitrage. However, whether it is CBESS or CRBESS, its energy arbitrage revenue accounts for no more than $10 \%$ of the total revenue, which shows that the change in battery capacity has little effect on BESS's revenue.

From BESS configuration optimization results, it is still beneficial to expand the scale of CBESS. The maximum NPV can be reached at 200MW/200MW, and there is still profit when the scale of CBESS reaches 300MW/300MWh. But CRBESS is the opposite. Expanding the scale of CRBESS will cause the NPV to decline continuously, and it will lose profitability at $150 \mathrm{MW} / 150 \mathrm{MWh}$. It is because CRBESS relatively increases its profitability by reducing costs. However, as the scale of CRBESS increases and the cost increases faster than the profitability rate, CRBESS cannot maintain its high profitability. It shows that the development space of new lithium-ion batteries is larger than that of lithium-ion SLB. It also indicates that CBESS has a more vital ability to cope with the risk of cost increment.

From the sensitivity analysis of project profitability and investment ability, CRBESS reduces the sensitivity of capital cost. However, the sensitive factors O\&M cost, price difference, PCS cost, and FCAS market price still significantly impact BESS's profitability and investment ability.

Overall, it is economically feasible to replace the new lithium-ion battery in CBESS with lithium-ion SLB from EV and build CRBESS. However, under the existing technical and market conditions, the expansion of CRBESS will be restricted economically. At present, the best way is to transform the existing CBESS into CRBESS or partially reconstruct it, which can maximize the benefits of BESS. In the future, CRBESS can combine artificial intelligence technology and big data technology to optimize the automatic dispatch deeply and accurately predict market demand and price changes, further improve economic performance.

\section{References}

1. P. S. M. Research, "Energy Storage Market to Reach \$26,137 Million by 2022," ed: GlobeNewswire, 2017.

2. P. Maloney, "Global energy storage market to hit $8.8 \mathrm{GW}$ by 2025 , IHS Markit says," ed: Utility Dive, 2017.

3. IEA(2020), "Energy Storage," IEA, Paris,June,2020, Available: https://www.iea.org/reports/energy-storage. 
4. S. E. C. (2018), "Australian Energy Storage market Analysis," Smart Energy CouncilSep, 2018, Available: https://www.smartenergy.org.au/sites/default/files/uploadedcontent/field_f_content_file/australian_energy_storage_market_analysis_report_sep18_ final.pdf.

5. C. Heymans, S. B. Walker, S. B. Young, and M. J. E. P. Fowler, "Economic analysis of second use electric vehicle batteries for residential energy storage and load-levelling," vol. 71, pp. 22-30, 2014.

6. A. Assunção, P. S. Moura, and A. T. J. A. e. de Almeida, "Technical and economic assessment of the secondary use of repurposed electric vehicle batteries in the residential sector to support solar energy," vol. 181, pp. 120-131, 2016.

7. J. Neubauer and A. J. J. o. P. S. Pesaran, "The ability of battery second use strategies to impact plug-in electric vehicle prices and serve utility energy storage applications," vol. 196, no. 23, pp. 10351-10358, 2011.

8. S. J. Tong, A. Same, M. A. Kootstra, and J. W. J. A. e. Park, "Off-grid photovoltaic vehicle charge using second life lithium batteries: An experimental and numerical investigation," vol. 104, pp. 740-750, 2013.

9. I. (2020), "Global EV Outlook 2020," IEA, , Paris, 2020, Available: https://www.iea.org/reports/global-ev-outlook-2020.

10. N. Jiao, "Second-life Electric Vehicle Batteries 2020-2030," IDTechEx, 2020, Available: https://www.idtechex.com/en/research-report/second-life-electric-vehicle-batteries2020-2030/681.

11. Y. Miao, P. Hynan, A. von Jouanne, and A. J. E. Yokochi, "Current Li-ion battery technologies in electric vehicles and opportunities for advancements," vol. 12, no. 6, p. 1074, 2019.

12. G. Albright, J. Edie, and S. J. A. E. e. I. Al-Hallaj, "A comparison of lead acid to lithiumion in stationary storage applications," 2012.

13. P. batteries, "Lithium Ferro Phosphate Batteries vs. VRLA Batteries," Available: https:/uploads-

ssl.webflow.com/5c51a75716d83a29793c37d9/5c875720506b27a023dff7d0_lithiumferro-phosphate-batteries-vs-vrla-batteries.pdf.

14. N. Omar et al., "Lithium iron phosphate based battery-Assessment of the aging parameters and development of cycle life model," vol. 113, pp. 1575-1585, 2014.

15. L. I. B. T. C. (2020), "Battery Testing Report 9," ITP Renewables, Sep, 2020, Available: https://batterytestcentre.com.au/wpcontent/uploads/BatteryTestingReport9Sept2020.pdf.

16. R. H. Byrne, T. A. Nguyen, D. A. Copp, B. R. Chalamala, and I. J. I. A. Gyuk, "Energy management and optimization methods for grid energy storage systems," vol. 6, pp. 13231-13260, 2017.

17. L. I. $\quad$ B. $\quad$ T. Centre, "Lithium Ion," Available: https://batterytestcentre.com.au/project/lithium-ion/.

18. A. (2019), "2019 Costs and Technical Parameter Review," AEMO, Dec 10, 2019, Available: https://www.aemo.com.au//media/Files/Electricity/NEM/Planning_and_Forecasting/Inputs-AssumptionsMethodologies/2019/Aurecon-2019-Cost-and-Technical-Parameters-Review-DraftReport.PDF. 
19. S. Tong, T. Fung, M. P. Klein, D. A. Weisbach, and J. W. J. J. o. E. S. Park, "Demonstration of reusing electric vehicle battery for solar energy storage and demand side management," vol. 11, pp. 200-210, 2017.

20. L. Ahmadi, A. Yip, M. Fowler, S. B. Young, R. A. J. S. E. T. Fraser, and Assessments, "Environmental feasibility of reuse of electric vehicle batteries," vol. 6, pp. 64-74, 2014.

21. J. Neubauer, A. Pesaran, B. Williams, M. Ferry, and J. Eyer, "Techno-economic analysis of PEV battery second use: Repurposed-battery selling price and commercial and industrial end-user value," National Renewable Energy Lab.(NREL), Golden, CO (United States)0148-7191, 2012.

22. L. Ahmadi et al., "Energy efficiency of Li-ion battery packs reused in stationary power applications," vol. 8, pp. 9-17, 2014.

23. L. Ahmadi, S. B. Young, M. Fowler, R. A. Fraser, and M. A. J. T. I. J. o. L. C. A. Achachlouei, "A cascaded life cycle: reuse of electric vehicle lithium-ion battery packs in energy storage systems," vol. 22, no. 1, pp. 111-124, 2017.

24. D. E. (2015), "DTE Energy Advanced Implementation of Energy Storage Technologies," DTE Energy, 2015, Available: https://www.smartgrid.gov/files/documents/OE0000229_DTE_FinalRep_2016_03_16. pdf.

25. L. I. B. T. Centre, "Retired Batteries," ITP Renewables, Available: https://batterytestcentre.com.au/retired-batteries/.

26. U. K. Debnath, I. Ahmad, D. J. I. J. o. E. P. Habibi, and E. Systems, "Quantifying economic benefits of second life batteries of gridable vehicles in the smart grid," vol. 63, pp. 577-587, 2014.

27. X. Zhao, Y. Zeng, and D. J. E. Zhao, "Distributed solar photovoltaics in China: Policies and economic performance," vol. 88, pp. 572-583, 2015.

28. K. Mongird et al., "Energy storage technology and cost characterization report," Pacific Northwest National Lab.(PNNL), Richland, WA (United States)2019.

29. M. Kleinberg, "Battery energy storage study for the 2017 IRP," ed: Pacificorp, 2016.

30. V. J. P. f. t. N. R. E. L. Black, "Cost and performance data for power generation technologies," 2012.

31. T. Aquino, M. Roling, C. Baker, and L. J. P. R. P. A. F. C. Rowland, CO, USA, "Battery Energy Storage Technology Assessment," p. 8, 2017.

32. R. Sioshansi, P. Denholm, T. Jenkin, and J. J. E. e. Weiss, "Estimating the value of electricity storage in PJM: Arbitrage and some welfare effects," vol. 31, no. 2, pp. 269277, 2009.

33. S. P. N. (2020), "2020-25 Tariff Structure Statement Part A," SA Power NetworksJune 2020, Available: https://www.sapowernetworks.com.au/public/download.jsp?id=9508.

34. A. (2015), "Guide to Ancillary Services in the National Electricity Market," AEMOApril, 2015, Available: https://www.aemo.com.au/-/media/Files/PDF/Guide-to-AncillaryServices-in-the-National-Electricity-Market.pdf.

35. A. (2019), "Battery Energy Storage System Requirements for Contingency FCAS Registration," AEMO Operations Department - Systems Performance \& Commercial, Jan 14, 2019, Available: https://www.aemo.com.au//media/Files/Electricity/NEM/Security_and_Reliability/Ancillary_Services/BatteryEnergy-Storage-System-requirements-for-contingency-FCAS-registration.pdf. 
36. A. (2019), "Large-Scale Battery Storage Knowledge Sharing Report," ARENASep, 2019, Available: https://arena.gov.au/assets/2019/11/large-scale-battery-storage-knowledgesharing-report.pdf.

37. A. (2019), "Regulation FCAS changes," AEMO2019, Available: https://aemo.com.au//media/Files/Electricity/NEM/Security_and_Reliability/Ancillary_Services/Frequencyand-time-error-reports/Regulation-FCAS-factsheet.pdf.

38. A. (2019), "Hornsdale Power Reserve Year 1 Technical and Market Impact Case Study," Aurecon2019, Available: https://www.aurecongroup.com/-/media/files/downloadslibrary/thought-leadership/aurecon-hornsdale-power-reserve-impact-study-2018.pdf.

39. M. i. (2019), "Tesla Battery in Australian NEM," Market Quality Dashboard2019, Available:

https://www.mqdashboard.com/insight/case_study_public/Tesla+Battery+in+the+Austr alian+NEM.

40. G. Desarnaud, "The second life battery cycle: after about 10 years in vehicle, lithium-ion batteries can be reused for another purpose and thereby begin a "second life"," CapgeminiApr 18, 2019, Available: https:/www.capgemini.com/2019/04/second-lifebatteries-a-sustainable-business-opportunity-not-a-conundrum/.

41. B. Bai, S. Xiong, B. Song, M. J. R. Xiaoming, and S. E. Reviews, "Economic analysis of distributed solar photovoltaics with reused electric vehicle batteries as energy storage systems in China," vol. 109, pp. 213-229, 2019.

42. S. P. N. (2019), "Tariff Price List," SA Power NetworksJul 31, 2020, Available: https://www.sapowernetworks.com.au/public/download.jsp?id=315323.

43. C. E. Institude, "LIthium-ion Battery," University of Washington, Available: https://www.cei.washington.edu/education/science-of-solar/battery-technology/.

44. X. Wang, G. Gaustad, C. W. Babbitt, K. J. R. Richa, Conservation, and Recycling, "Economies of scale for future lithium-ion battery recycling infrastructure," vol. 83, pp. 53-62, 2014. 